\title{
Formación inicial de los espermatofóros en el testículo del cangrejo Uca uruguayensis (Brachyura: Ocypodidae)
}

\author{
Elena I. Cuartas ${ }^{1}$ \& A.M. Petriella ${ }^{2}$ \\ 1 Departamento de Biología, Facultad de Ciencias Exactas y Naturales, Universidad Nacional de Mar del Plata. Funes \\ 3350-B7602AYL, Mar del Plata, Argentina; ecuartas@mdp.edu.ar \\ 2 Departamento de Ciencias Marinas, Facultad de Ciencias Exactas y Naturales, Universidad Nacional de Mar del Plata. \\ Funes 3350-B7602AYL, Mar del Plata, Argentina. CONICET.
}

Recibido 12-X-2005. C Corregido 29-VI-2006. Aceptado 16-III-2007.

\begin{abstract}
Initial formation of spermatophores in the testicles of the crab Uca uruguayensis (Brachyura: Ocypodidae). The functional anatomy of the male reproductive system of Uca uruguayensis from Mar Chiquita

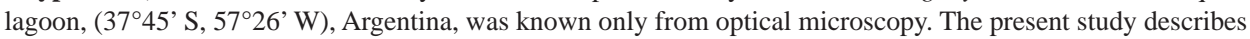
the participation of vas deferens regions in spermatophore formation. A detailed description of the functional morphology of the different regions of the testicular lobes was carried out using both light and scanning electron microscopy. Spermatophore formation begins at the base of the testicular lobe. In most brachyuran species, the spermatophore starts formation when spermatozoa move from the collecting ducts of the testis to the vas deferens. However, in $U$. uruguayensis observations suggest that the formation of the spermatophore walls occurred in the terminal region of the testis, and that the spermatophore was formed at the junction of the testis and the vas deferens. Rev. Biol. Trop. 55 (Suppl. 1): 9-14. Epub 2007 June, 29.
\end{abstract}

Key words: Crustacea, Decapoda, Uca, functional morphology, reproductive system, spermatophore.

El período reproductivo de Uca uruguayensis en la laguna de Mar Chiquita, Argentina, es breve. Spivak et al. (1991) citan la presencia de hembras ovígeras sólo en el mes de febrero de 1989, mientras que Gómez et al. (2003) encontraron hembras ovígeras entre fines de diciembre y febrero. Sastry (1983) menciona que las hembras de Brachyura desovan por lo general dos o tres veces por estación reproductiva; Yamaguchi (2002) observó en Uca lactea que la cópula se realiza en las cuevas de las playas con un solo macho. Por su parte, Diesel (1991) sugiere que las hembras de Brachyura pueden ser fecundadas por más de un macho o retener el esperma entre estaciones de puesta, pudiendo liberar los huevos inmediatamente después de la cópula o con un retraso entre inseminación y fecundación. En el caso de la población de $U$. uruguayensis de la Laguna de Mar Chiquita, no se ha establecido aún la modalidad de fecundación y puesta.

El tracto reproductor masculino de los Ocypodidae es similar al descrito para otros cangrejos Brachyura. La espermatogénesis se inicia en los lóbulos testiculares y los espermatozoides, durante su trayecto por el vaso deferente (VD), quedan rodeados por una membrana exterior amorfa y son incluidos en el fluido seminal, formando el espermatóforo (Hinsch 1988). La complejidad de la estructura del espermatóforo permite que la hembra retenga espermatozoides que fecunden ovocitos (Anilkumar et al. 1999) en aquellas especies con desoves sucesivos.

Con respecto a la formación de los espermatóforos en crustáceos Brachyura, hasta 
el momento se proponen dos mecanismos: Hinsch (1988) sostiene que los espermatóforos se forman en el VD durante el descenso hacia la ampolla terminal. Por otra parte, Moriyasu et al. (2002), trabajando con Cancer borealis, postulan que la formación del espermatóforo se inicia en la base de los lóbulos testiculares en la zona de contacto con el VD.

Como parte de estudios previos sobre la estructura del sistema reproductor de $U$. uruguayensis (Cuartas y Petriella 2004), se reconocieron histológicamente dos zonas en el VD: la anterior (VDA), próxima al testículo, y la posterior (VDP). También se observó, en la base de los lóbulos testiculares, el inicio de la agrupación de las células germinales en maduración. En el presente trabajo se describe la morfología funcional de las diferentes estructuras involucradas, con el propósito de definir la secuencia de formación del espermatóforo de $U$. uruguayensis, empleando microscopía óptica, electrónica de barrido (MEB) y de transmisión (MET).

\section{MATERIALES Y MÉTODOS}

Se recolectaron machos adultos (14-18 mm de ancho de caparazón) de U. uruguayensis en la parte superior de la costa de la laguna de

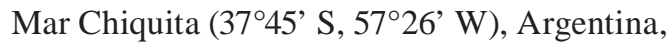
durante la época reproductiva (febrero de 2005). Se trabajó con individuos sexualmente activos, empleando como indicador macroscópico la dilatación del vaso deferente. Se analizaron histológicamente testículos y VDA con fijación en mezcla de Davidson (formol, ácido acético, agua) (Bell y Lightner 1988) e inclusión en parafina; los cortes de 3-5 $\mu \mathrm{m}$ fueron deshidratados en concentración creciente de alcoholes y coloreados con hematoxilina-eosina (H\&E) y azul de toluidina (AT). El material destinado a la observación con MEB se fijó a $4{ }^{\circ} \mathrm{C}$ en glutaraldehido al $2.5 \%$ en $0.1 \mathrm{M}$ buffer cacodilato a $\mathrm{pH}$ 7. $\mathrm{La}$ deshidratación se realizó en una serie creciente de alcoholes y para el secado se utilizó HMDS (Hexamethyldisilazane, Fluka ${ }^{\circledR}$ ), en reemplazo del punto crítico. Las muestras se montaron en tacos de aluminio y se metalizaron con AU/PL (oro-paladio), usando para la observación un ultramicroscopio JEOL 6460.

El material para observación en MET se fijó en glutaraldehído al $2.5 \%$, en buffer cacodilato de Na $0.1 \mathrm{M}$ (pH=7.2-7.4). La postfijación se realizó en $\mathrm{OsO}_{3}$ con posterior inclusión en Spurr y coloración en acetato de uranilo y citrato de plomo. Los cortes fueron examinados en un microscopio Hitachi HU 11C-1.

\section{RESULTADOS}

Los testículos pares se localizan en la cavidad torácica, dorsales al hepatopáncreas; están formados por numerosos lóbulos asociados a túbulos colectores (Fig. 1A, B).
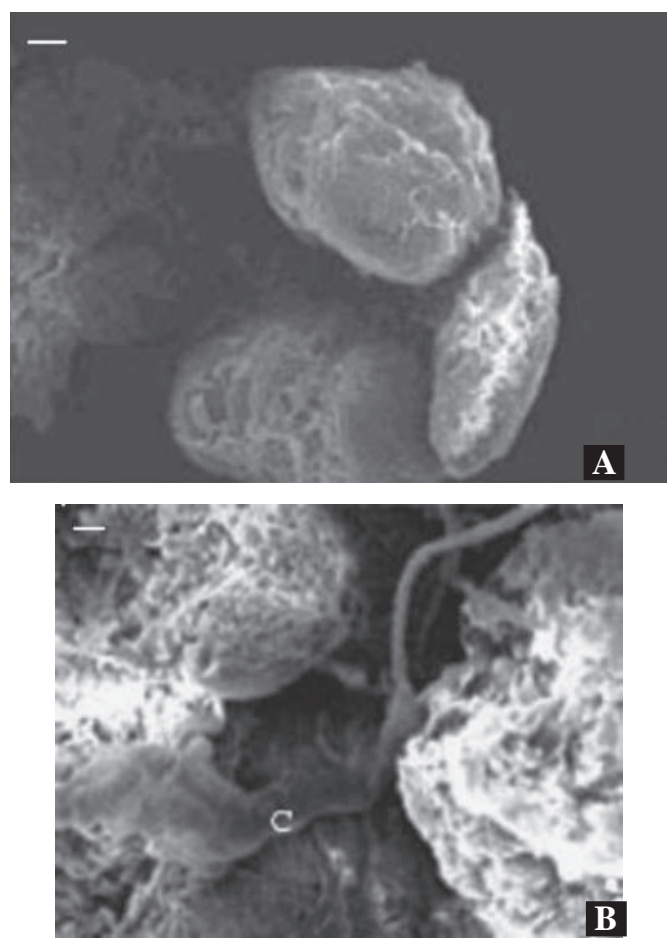

Fig. 1. Vista general de los lóbulos testiculares de Uca uruguayensis y su relación con los conductos asociados (MEB). A. Lóbulos de la zona apical del testículo. Escala: $50 \mu \mathrm{m}$. B. Conducto colector del lóbulo testicular C. (MEB). Escala: $20 \mu \mathrm{m}$

Fig. 1. General view of testicular lobes of Uca uruguayensis and associated ducts (SEM). A. Apical zone of testicular lobes. (SEM). Scale bar: $50 \mu \mathrm{m}$. B. Collecting duct of a testicular lobe C. Scale bar: $20 \mu \mathrm{m}$ 
Anatómicamente, se encuentran en estrecha relación con el hepatopáncreas. Externamente los lóbulos y los conductos colectores están recubiertos por una capa de tejido conectivo (Fig. 2A). En el testículo coexisten grupos de células germinales en diferentes grados de espermatogénesis; sin embargo, en cada grupo la espermatogénesis es sincrónica, observándose que siempre persiste un núcleo de espermatogonias, generalmente en disposición periférica (Fig. 2B). Testículos y conductos colectores están limitados internamente por un tejido epitelial simple; la cubierta externa de tejido conectivo ingresa en los lóbulos formando la pared que delimita los grupos de células germinales (Fig. 2B, C).

Durante la maduración de las células germinales, en cada grupo se genera un espacio lateral (Fig. 2B) que precede a la formación de los conductos colectores (Fig. 2C), los cuales confluyen formando el VD. En la zona de contacto del VDA con el testículo, se localizan células germinales (espermátidas en diferentes grados de maduración). En la figura 2C se observa la presencia de una sustancia amorfa que indica el inicio del empaquetamiento de las células germinales. En la región inicial del VDA se visualizan las espermátidas agrupadas en espermatóforos en formación; a este nivel, los espermatóforos tienen paredes lisas, de espesor variable (Fig. 2D).

Internamente en la base de un lóbulo testicular se advierten los espermatóforos de paredes lisas, en una fase temprana de aglutinación, separados por una escasa matriz extracelular (Fig. 2E). Este material, denso y opaco, no se considera todavía fluido seminal. Los espermatozoides maduros se observaron en cortes del VDP (Fig. 2F).

\section{DISCUSIÓN}

El ciclo reproductivo de la población de $U$. uruguayensis de la laguna de Mar Chiquita se extiende desde principios del mes de febrero hasta fines de marzo, pero el ciclo de madurez testicular se inicia en los meses de octubre-noviembre (Gómez Cassou 2005). En machos en reposo sexual (setiembre) los acinos testiculares se presentan como estructuras compactas, observándose las células en los primeros estadios de la gametogénesis; al iniciarse la época reproductiva (noviembre) los acinos tienen una estructura laxa (obs. pers.).

En otras especies como el cangrejo Telmessus cheiragonus pueden reconocerse seis estadios de maduración de las células germinales en los lóbulos testiculares (Nagao y Munehara 2003). En U. uruguayensis solo se reconocieron tres (obs.pers.).

Tradicionalmente, se postula que en los crustáceos decápodos el vaso deferente es la estructura responsable del "empaquetamiento" de los espermatozoides y de la formación definitiva del espermatóforo (Krol et al. 1992). Sin embargo, Moriyasu et al. (2002), trabajando con Cancer borealis, describieron el comienzo de la formación de los espermatóforos en los lóbulos terminales del testículo. Refiriéndonos a U. uruguayensis, la observación de una masa de espermátidas encerradas en una lámina de una sustancia amorfa en los colectores del testículo, sugirió un mecanismo de formación del espermatóforo similar al propuesto por Moriyasu et al. (2002). Si bien la transición de espermatóforos de superficie "arrugada" a lisa en el testículo de $U$. uruguayensis no es tan clara como la observada por Benhalima y Moriyasu (2000) en el VD de Chionocetes opilio, hay que tener en cuenta que las imágenes analizadas en nuestro trabajo se refieren a la etapa inicial de la formación, homologable al estadio inmaduro según lo interpretan Beninger et al. (1988) para C. opilio.

Sainte Marie y Sainte Marie (1999) mencionaron para C. opilio que los espermatóforos encierran espermátidas inmaduras y maduras, espermatozoides inmaduros o formas intermedias entre estos tres tipos celulares. Esta propuesta concuerda con lo encontrado en $U$. uruguayensis, especie en la que se observa en el VDA espermatóforos encerrando espermátidas en distinto grado de maduración; en el VDM y el VDP los espermatóforos incluyen 

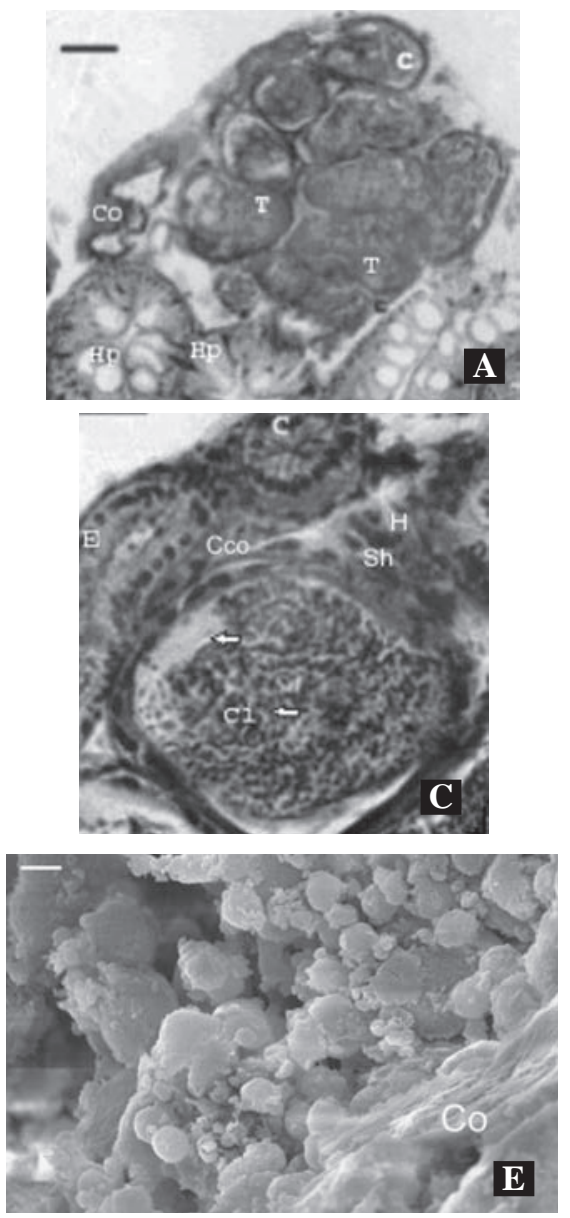
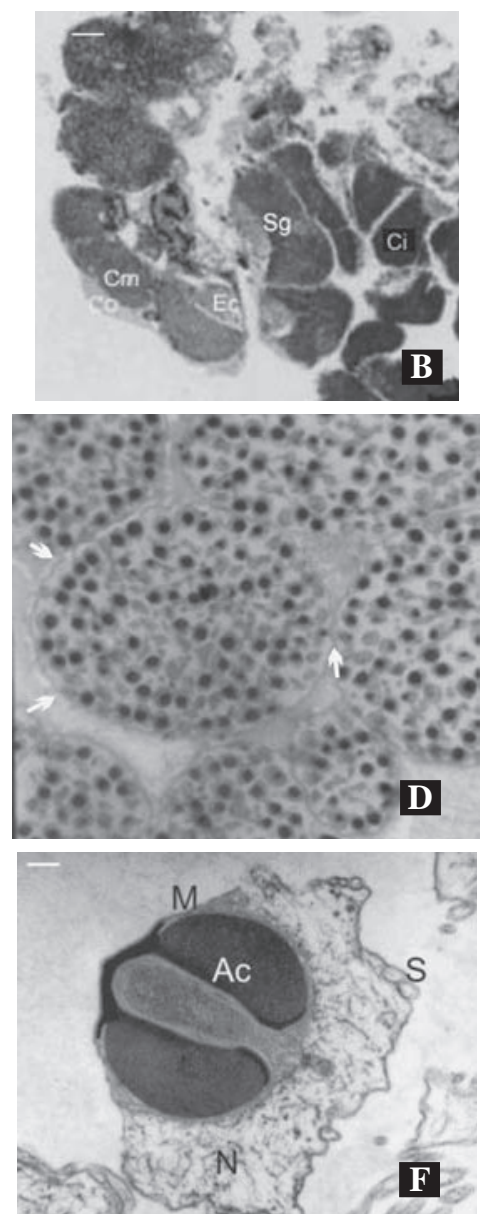

Fig. 2. Estructura del testículo y del espermatozoide de Uca uruguayensis. A. Corte de un testículo (MO) que muestra la relación de los lóbulos testiculares (T) con el hepatopáncreas (Hp). C, zona de formación de un conducto colector. Co, conectivo que rodea el órgano. H\&E. Escala: $50 \mu \mathrm{m}$. B. Corte longitudinal de lóbulos testiculares (MO). Ci, grupos de células germinales en diferenciación temprana. Cm, grupos de células germinales avanzadas con espermatogonias (Sg). Co, tejido conectivo externo. C, zona de formación de un conducto colector. H\&E. Escala: 80 $\mu \mathrm{m}$. C. Corte transversal de un lóbulo testicular en la zona de transición entre el conducto colector y el VDA (MO). Cco, conectivo que rodea el colector. E, epitelio de los colectores. Sh, seno hemal. H, hemocitos. Se señala (flechas) la presencia de una sustancia amorfa que indica el inicio del empaquetamiento de las células germinales en etapa de espermatocito II o espermátida. H\&E. Escala: $20 \mu \mathrm{m}$. D. Corte transversal de VDA, en la zona de contacto con los conductos colectores, con numerosos espermatóforos (AT). Escala: 20 $\mu \mathrm{m}$. E. Fractura de un lóbulo testicular en la zona media (MEB). Co, Pared de conectivo Escala: $20 \mu \mathrm{m}$. F. Morfología del espermatozoide (MET). AC, Acrosoma. M, membrana plasmática. N, núcleo. S, espinas “spikelike arms”. Escala: $0.8 \mu \mathrm{m}$.

Fig. 2. Structure of Uca uruguayensis testes and spermatozoan. A. Testis cross section (OM), notice the relation between the testicuar lobes $(\mathrm{T})$ and hepatopancreas (Hp). C, origin zone of a collecting duct. Co, external connective tissue. H\&E Scale bar $=50 \mu \mathrm{m}$. B. Longitudinal section of testicular lobes (OM). Ci, germinal cells in early differentiation. Cm, mature germinal cells. Sg, spermatogonia. Co, external connective tissue. C, origin zone of a collecting duct. H\&E. Scale bar: $80 \mu \mathrm{m}$. C. Cross section of testicular lobes at the junction between the collecting duct and the AVD (OM). Cco, connective tissue surrounding the collecting duct. E, collecting duct epithelium. Sh, haemal sinuses. H, haemocytes. Amorphous substance (arrows) indicating the beginning of germinal cells packing. H\&E Scale bar: $20 \mu \mathrm{m}$. D. Cross section of AVD, at the junction with collecting duct, showing numerous spermatophores. TB Scale bar: $20 \mu \mathrm{m}$. E. Fracture of a testicular lobe at the medial zone (SEM). Co, connective wall. Scale bar: $20 \mu \mathrm{m}$. F. Spermatozoan morphology (TEM). AC, acrosome. M, plasma membrane. $\mathrm{N}$, nucleus. S, spike-like arms. Scale bar: $0.8 \mu \mathrm{m}$ 
espermatozoides inmaduros y maduros, distinguibles por la variación de la relación acrosoma/núcleo (obs. pers).

Aún cuando la formación del espermatóforo en $U$. uruguayensis se inicia en el testículo, se manifiesta un proceso similar al conocido para otras especies de Brachyura (Moriyasu et al. 2002), en las que a medida que se desplaza hacia la zona basal del lóbulo testicular, aumenta la cantidad y densidad de la matriz extracelular.

Esta formación inicial en el testículo permitiría completar la maduración de los espermatóforos en un VD más corto y menos sinuoso que el mencionado para otras especies (Hinsch 1988) y podría estar vinculada con la estrategia reproductiva de la especie, con maduración gonadal limitada a una sola época anual, en el período estival.

\section{RESUMEN}

La anatomía funcional del sistema reproductor de los machos de Uca uruguayensis de la población de la laguna de Mar Chiquita (37²4' S, 57²6’ W), Argentina, ha sido previamente estudiada empleando microscopía óptica. En el presente estudio se demostró la intervención del vaso deferente, en sus distintas regiones, en la formación del espermatóforo y la inclusión del fluido espermático. Se amplía la descripción de la morfología funcional de las regiones de los lóbulos testiculares (empleando también microscopía electrónica de barrido). La formación de los espermatóforos se inicia en la base del lóbulo testicular. El mecanismo descrito hasta el momento para la mayor parte de las especies de braquiuros postula que los espermatóforos comienzan a formarse cuando los espermatozoos pasan de los colectores del testículo al vaso deferente. Nuestras observaciones sugieren sin embargo, que en esta especie la formación de la pared del espermatóforo se inicia en la base de los lóbulos testiculares, y que los espermatóforos están completamente formados en la unión de los testículos y el vaso deferente anterior.

Palabras clave: Crustacea, Decapoda, Uca, morfología funcional, reproductor, espermatóforo

\section{REFERENCIAS}

Anilkumar, G., K. Sudha \& T. Subramonian. 1999. Spermatophore transfer and sperm structure in the brachyuran crab Metopograpsus messor (Decapoda: Grapsidae). J. Crust. Biol. 19: 361-370.

Bell, T.A. \& D.V. Lightner. 1988. A Handbook of Normal Penaeid Shrimp Histology. World Aqua. Soc. Allen Press, Lawrence, Kansas, EEUU. 144 p.

Benhalima, K. \& M. Moriyasu. 2000. Structure and function of the posterior vas deferens of the snow crab, Chionoecetes opilio (Brachyura, Majidae). Invertebr. Reprod. Dev. 37: 11-23.

Beninger, P.G., R.W. Elner, T.P. Foyle \& P.H. Odense. 1988. Functional anatomy of the male reproductive system and female spermatheca in the snow crab Chionoecetes opilio (Fabricius) (Decapoda: Majidae) and a hypothesis for fertilization. J. Crust. Biol. 8: 322-332.

Cuartas, E.I. \& A.M. Petriella. 2004. Estructura del vaso deferente del cangrejo violinista Uca uruguayensis (Brachyura, Ocypodidae). Universidad Católica del Norte, Coquimbo, Chile. p. 218.

Diesel, R. 1991. Sperm competition and the evolution of mating behaviour in Brachyura, with special reference to spider crabs (Decapoda, Majidae), p. 145163. In R.T. Bauer \& J.W. Martin (eds.). Crustacean Sexual Biology. Columbia University, Nueva York, EEUU.

Gómez Cassou, M. 2005. Morfología funcional del aparato reproductor de Uca uruguayensis (DecapodaBrachyura). Interrelación con el hepatopáncreas. Tesis de Grado, Universidad Nacional de Mar del Plata, Mar del Plata, Argentina. 40 p.

Gómez, M., E.I. Cuartas \& A.M. Petriella. 2003. Description of the reproductive system of Uca uruguayensis (Crustacea: Decapoda). Biocell 27: 243.

Hinsch, G.W. 1988. Ultrastructure of the sperm and spermatophores of the golden crab Geryon fenneri and a closely related species, the red crab G. quinquedens, from the eastern Gulf of Mexico. J. Crust. Biol. 8: 333-339.

Krol, R.M., W.E. Hawkins \& R.M. Overstreet. 1992. Reproductive components, p. 295-343. In F.W. Harrison (ed.). Microscopic Anatomy of Invertebrates. Vol.10. Decapod Crustacea. Wiley-Liss, Nueva York, EEUU.

Moriyasu, M., K. Benhalima, D. Duggan, P. Lawton \& D. Robichaud. 2002. Reproductive biology of male jonah crab, Cancer borealis Stimpson, 1859 (Decapoda, Cancridae) on the Scotian shelf, northwestern Atlantic. Crustaceana 75: 891-913. 
Nagao, J. \& H. Munehara. 2003. Annual cycle of testicular maturation in the helmet crab Telmessus cheiragonus. Fish. Sci. 69: 1200-1208.

Sainte-Marie, G. \& B. Sainte-Marie. 1999. Reproductive products in the adult snow crab (Chionoecetes opilio). I. Observations on spermiogenesis and spermatophore formation in the vas deferens. Can. J. Zool. 77: 440-480.

Sastry, A. N. 1983. Ecological aspects of reproduction, p. 179-270. In D.E. Bliss (ed.). The Biology of the Crustacea. Vol. 8. Academic, Nueva York, EEUU.
Spivak, E.D, M.A. Gavio \& C.E. Navarro. 1991. Life history and structure of the world's southernmost Uca population: Uca uruguayensis (Crustacea, Brachyura) in Mar Chiquita lagoon (Argentina). Bull. Mar. Sci. 48: 679-688.

Yamaguchi, T. 2002. The mating system of the fiddler crab, Uca lactea (Decapoda, Brachyura, Ocypodidae). Crustaceana 74: 389-400. 